\title{
CLINICO-PATHOLOGICAL CHARACTERISTICS OF LUPUS NEPHRITIS IN EASTERN ZONE OF INDIA: A SINGLE TERTIARY CENTER EXPERIENCE
}

\author{
SMARAKA R PANDA ${ }^{1}$, CHITTARANJAN KAR ${ }^{1}$, PRASANT KUMAR SAHU ${ }^{1}$, SASHIBHUSAN ROUT ${ }^{1}$ \\ BISHWARANJAN MOHANTY ${ }^{1}$, TAPAS RANJAN BEHERA ${ }^{1}$, SUDESHNA BEHERA ${ }^{2 *}$
}

${ }^{1}$ Department of Nephrology, SCB Medical College, Cuttack, Odisha, India. ${ }^{2}$ Department of Biochemistry, IMS and SUM Hospital, Siksha 'o' Anusandhan University, Bhubaneswar, Odisha, India. Email: 4sudeshna@gmail.com

Received: 03 May 2016, Revised and Accepted: 11 May 2016

ABSTRACT

Objective: Lupus nephritis (LN) is the most common and serious manifestation of systemic lupus erythematosus (SLE) and an important cause of morbidity and mortality. Although diagnosis of LN is straight forward in a patient with SLE and proteinuria, and active urine sediment and perhaps renal insufficiency, still renal biopsies are required at diagnosis to enable classification of nephritis severity, to provide prognostic information, and to guide treatment. Hence, the objective of this study is to determine the frequency of distribution of different classes of LN based on renal biopsy reports and to correlate it with various laboratory findings.

Methods: Retrospective study was done in all patients with LN who had at least one representative renal biopsy and evaluated in Nephrology Department of SCB Medical College, Cuttack, in 6-month duration. Various laboratory values were recorded and correlated with histopathological lupus classifications.

Results: Out of 35 patients enrolled, 33 (94.28\%) were females and 2 (5.71\%) were males. Mean age was $27.53 \pm 12.26$ years. Majority of cases belong to Class IV followed by Class V. Patients of Class IV LN have a significantly low hemoglobin level. Similarly, serum urea and creatinine are higher in Group IV than other groups, and serum creatinine was found to be significant. 24 hrs urinary protein excretion has a significant correlation with the classes of LN.

Conclusion: This study suggests some meaningful correlation between laboratory findings and histopathological lupus classification. This study also suggests that renal biopsies are still beneficial for better evaluation of renal status and determination of LN classes.

Keywords: Clinico-pathological correlation, Lupus nephritis, Biopsy.

(C) 2016 The Authors. Published by Innovare Academic Sciences Pvt Ltd. This is an open access article under the CC BY license (http://creativecommons. org/licenses/by/4. 0/) DOI: http://dx.doi.org/10.22159/ajpcr.2016.v9i5.13112

\section{INTRODUCTION}

Systemic lupus erythematosus (SLE) is a chronic disease with autoimmune pathogenesis and manifests as a low-grade inflammation and may advance to multiorgan fatal damage [1]. The disease prevalence differs globally. The annual incidence of SLE in relatively low- to highrisk groups varies from 6 to 35 cases per 100,000 populations [2,3]. The first case of SLE was reported from India in 1965. Reported prevalence in northern Indian population ranges from 14 to $60 / 100,000$ [4].

The inflammatory involvement of SLE virtually affects every organ including the joints, skin, kidney, brain, serosa, lungs, heart, and gastrointestinal tract. Renal involvement of SLE, known as lupus nephritis (LN) is a common manifestation and often determines the course of the disease. It is also an important cause of morbidity and mortality in SLE patients. The incidence of LN in SLE is divergent around the world and may be related to different ethnic and genetic backgrounds.

Nearly $70-80 \%$ of all cases of SLE have some clinical manifestations of LN mostly glomerulonephritis [5]. Proteinuria and deterioration of renal function were the main indications for renal biopsy. Although diagnosis of LN is straight forward in a patient with SLE and proteinuria, and an active urine sediment and perhaps renal insufficiency, abnormal renal pathology can also occur in the absence of proteinuria or active urine sediment [6]. For this reason, renal biopsies are required at diagnosis to enable classification of nephritis severity, according to the International Society of Nephrology and Renal Pathology Society (ISN-RPS) criteria [7], to provide prognostic information, and to guide treatment. Hence, there is a need for performing renal biopsies to accurately determine the extent of parenchyma damage in LN and to guide treatment.
As there generally exist a good correlation between clinical and hematological presentations with renal biopsy in patients with $\mathrm{LN}$, so it is of utmost importance to correlate the clinical and pathological data in patients with LN for the proper management and prognostication. Again this type of correlative study will help in better understanding of the pathophysiology of renal involvement in this disease.

Numerous studies are available on the clinico-pathological correlation in LN patients mainly from developed countries. However, regarding this, there are very few publications currently available in a developing country in India and probably no such data has been published in Odisha (an Eastern state of India) till date.

Therefore, this study was aimed to assess the basic laboratory features of LN patients of eastern zone of India with biopsy-proven LN class, according to ISN/RPS 2003 classification.

\section{METHODS}

A retrospective study was done in all patients with $L N$ who had at least one representative renal biopsy and evaluated in Nephrology Department of SCB Medical College, Cuttack, in 6-month duration. All biopsies with at least 10 glomeruli were reviewed. For the patients who had repeated biopsies, samples and laboratory records of the first biopsy were used. Each biopsy was classified according to ISN/RPS 2003 classification system.

Available medical charts of the patients were reviewed. The laboratory values were recorded at the time of biopsy for each patient including hemoglobin level, white blood cell count, serum total protein, albumin, 
urea, creatinine, triglycerides, cholesterol, urinalysis, and 24 hrs urine protein excretion.

For statistical analysis SPSS computer program was used to determine whether there was an association between the laboratory parameters and ISN/RPS classification. Values were calculated by student's $t$-test and analysis of variance. $\mathrm{p}<0.05$ was considered to be statistically significant

\section{RESULTS}

Total 35 patients who fulfilled the American Rheumatism Association criteria for SLE and underwent renal biopsy were included in the study. There was a female preponderance in the studied patients, and only two of them were found to be male. Age of the patients ranges from 6 years to 55 years with a mean age of $27.53 \pm 12.26$ years.

As per Table 1, maximum number patients fall in the age group of 21-40 years and only 4 were $>40$ years of age.

Table 2 shows the distribution of renal biopsies according to ISN/RPS 2003 classification. It is apparent from the study that majority of cases belong to Class IV followed by Class V. No patient was found to be having Class I or Class VI.

Table 1: Distribution of age in groups $(n=35)$

\begin{tabular}{ll}
\hline Age in groups' (years) & Frequency (\%) \\
\hline$\leq 20$ & $9(25.71)$ \\
$21-40$ & $22(62.85)$ \\
$>40$ & $4(11.42)$ \\
Total & $35(100)$ \\
\hline
\end{tabular}

Table 2: Frequency of distribution of different classes of lupus nephritis according to ISN/RPS 2003 Classification

\begin{tabular}{ll}
\hline ISN/RPS classes & Frequency (\%) \\
\hline Class I & $0(0)$ \\
Class II & $3(8.57)$ \\
Class III & $6(17.14)$ \\
Class IV & $19(54.28)$ \\
Class V & $7(36.84)$ \\
Class VI & $0(0)$ \\
\hline
\end{tabular}

Distribution of various laboratory tests including hematology, biochemistry, and urine analysis among different stages of LN has been shown in Table 3. As no patient was found to be having Stage I and VI in our study population, so these two groups were not included in this table.

Anemia was observed mainly in Class IV and V. Severe anemia in Class IV $(8.55 \pm 1.2)$ was statistically significant $(p=0.03)$ when compared with other 3 groups. Serum urea and creatinine were studied as renal parameters. These two parameters are higher in Group IV than other groups, and serum creatinine was found to be significant. Serum protein and albumin levels were low in all groups.

Albuminuria was observed in all 4 Classes of LN ranging from traces to +4 . There was a significant correlation between $24 \mathrm{hrs}$ proteinuria and ISN/RPS 2003 classification $(\mathrm{p}=0.04)$.

\section{DISCUSSION}

LN remains one of the most severe manifestations of SLE and associated with substantial morbidity and mortality. The glomerular lesions that frequently accompany SLE have been the subject of intense investigation by clinicians and pathologists for nearly a half of century.

This study was conducted to find out the frequency of distribution of various stages of $\mathrm{LN}$ and to correlate different laboratory parameters with these stages.

Out of 35 subjects, 33 were females and 2 were male patients with a female:male ratio of $16: 1$. In the present study, the female preponderance might be due to small sample size which was only 35 or due to lack of registry of male patients during last 6 months study period. In another study conducted Sanker et al., all the patients were found to be females [8]. Various other studies also showed female preponderance in the study population [9-11]. Increased frequency of SLE among women may be attributed to differences in the metabolism of sex hormones and/or gonadotropin-releasing hormones.

Mean age of the study group patients at presentation was found to be $27.53 \pm 12.26$ years. Approximately similar results were obtained in different parts of India by Shobha et al. [12], where mean age of SLE patients was found to be $28.31 \pm 10.62$ years and Sanker et al. [8] (mean age $=28.42$ ). In fact, SLE is a disease of childbearing age. Some authors such as Esdaile et al. and Austin et al. have found out that younger age ( $<23$ years) is one of the indicators associated with increased rate of renal failure and a more rapid progressive course $[10,13]$.

Table 3: Histopathological classification of laboratory parameter

\begin{tabular}{|c|c|c|c|c|c|}
\hline \multirow[t]{2}{*}{ Laboratory parameters } & \multicolumn{4}{|c|}{ Histopathological classifications (mean \pm SD) } & \multirow[t]{2}{*}{$\mathbf{p}$} \\
\hline & Grade II $(n=3)$ & Grade III $(n=6)$ & Grade IV (n=19) & Grade V $(n=7)$ & \\
\hline Hemoglobin (g\%) & $12.4 \pm 2.38$ & $10.58 \pm 1.5$ & $8.57 \pm 1.2$ & $9.28 \pm 1.5$ & $0.03 *$ \\
\hline Serum urea $(\mathrm{mg} / \mathrm{dl})$ & $20 \pm 10.3$ & $59 \pm 35.8$ & $91.3 \pm 63.5$ & $45 \pm 21.8$ & 0.19 \\
\hline Serum creatinine $(\mathrm{mg} / \mathrm{dl})$ & $0.97 \pm 0.47$ & $1.56 \pm 1.40$ & $3.13 \pm 1.7$ & $1.13 \pm 0.55$ & $0.02 *$ \\
\hline Serum protein $(\mathrm{g} \%)$ & $5.8 \pm 1.2$ & $4.83 \pm 1.39$ & $5.02 \pm 0.78$ & $5.1 \pm 0.68$ & 0.78 \\
\hline Serum albumin $(\mathrm{g} \%)$ & $2.7 \pm 0.6$ & $2.6 \pm 1.09$ & $2.28 \pm 0.53$ & $2.37 \pm 0.37$ & 0.70 \\
\hline Serum cholesterol (mg/dl) & $168 \pm 56.5$ & $257.3 \pm 62.7$ & $227.7 \pm 87.7$ & $216.2 \pm 26.1$ & 0.63 \\
\hline Serum triglyceride $(\mathrm{mg} / \mathrm{dl})$ & $134 \pm 29.2$ & $216.16 \pm 45.6$ & $224.7 \pm 216.2$ & $168.4 \pm 33.6$ & 0.7 \\
\hline \multicolumn{6}{|l|}{ Urine analysis } \\
\hline \multicolumn{6}{|l|}{ Urine albumin } \\
\hline Traces & $1(33.3 \%)$ & $2(33.33 \%)$ & - & $1(14.28 \%)$ & \\
\hline+ & $2(66.6 \%)$ & - & $4(21 \%)$ & $2(28.57 \%)$ & \\
\hline++ & - & $2(33.33 \%)$ & $7(36.8 \%)$ & $3(42.8 \%)$ & \\
\hline+++ & - & $2(33.33 \%)$ & $6(31.5 \%)$ & $2(28.57 \%)$ & \\
\hline++++ & - & - & $1(5.26 \%)$ & - & \\
\hline 24 hrs urine protein (g/day) & $3.28 \pm 2.17$ & $2.04 \pm 2.31$ & $7.45 \pm 4.77$ & $5.64 \pm 3.21$ & $0.03^{*}$ \\
\hline Urine RBC (+) & $1(33.3 \%)$ & $5(83.3 \%)$ & $10(52.6 \%)$ & $4(57.14 \%)$ & \\
\hline Urine WBC $(+)$ & $1(33.3 \%)$ & $3(50 \%)$ & $12(63.15 \%)$ & $5(71.4 \%)$ & \\
\hline
\end{tabular}

${ }^{*} \mathrm{p}<0.05$ - significant 
On observing Table 2, we found none of the subjects were included in Class I or VI. Class IV is the most common histological type (54.28\%) of $\mathrm{LN}$ in this zone. This finding is in agreement with some previous studies where Group IV was found to be the most common variety $[5,12,14,15]$. Neumann et al. in his study on $150 \mathrm{LN}$ patients found out a frequency of $10 \%, 17 \%, 53 \%$, and $14 \%$ for the Class of II, III, IV, and V, respectively [16]. Similarly, Pollak and Pirani conducted their study on $376 \mathrm{LN}$ patients and observed the overall frequency of Class II, III, IV, and $V$ to be $26 \%, 19 \%, 37 \%$, and $15 \%$, respectively [17]. On the other hand, some researchers such as Apple et al. and Austin et al. found Class II and III as the more frequent groups $[18,19]$.

On studying Table 3, anemia was found to be statistically significant in Class IV as compared to other classes. Similar findings were observed by Shobha et al. [12]. In the study by Austin et al. [19], anemia was found to be individually associated with an increased probability of renal insufficiency as seen in Class IV. This is probably explained by a higher risk for development of anemia secondary to renal failure and active hematuria in Class IV. No significant correlation was seen in the case of leukocyte count with any class of LN. However, according to Esdaile et al., low platelet count was associated with renal insufficiency $(\mathrm{p}=0.04)$ on multivariant analysis.

Serum urea level was found to be higher, whereas serum creatinine was found to be significantly higher in Class IV similar to the study by Nezhad and Sepaskhah [5] and Mok et al. [20], who also observed a significant correlation of WHO classification and renal function. This could be explained by the severity of renal lesion in Class IV. One previous study reported that creatinine $>2.4 \mathrm{mg} / \mathrm{dl}$ is associated with poor survival outcome reflecting more severe renal damage [21]. According to another study by Yoo et al., more cases of Class IV showed progression to severe lesion on subsequent biopsy with an increase in serum creatinine level [22].

In our study, the highest protein excretion was found in Class IV. Correlation between 24 hrs urine protein excretion and ISN/RPS 2003 classes was found to be statistically significant and is in agreement with the study by Nezhad and Sepaskhah [5], who also found significantly elevated $24 \mathrm{hrs}$ urine protein excretion. Our study contradicts the result of Mok et al. where no significant correlation was found between $24 \mathrm{hrs}$ urinary protein excretion and WHO classes [20]. Our study also showed a higher incidence of leukocyturia in Class IV as compared to other classes.

We conclude that our study suggests some meaningful correlation between laboratory findings and histopathological lupus classification on renal biopsy. This study also suggests that renal biopsies are still beneficial for better evaluation of renal status and determination of LN classes. However, there are some limitations of the present study mainly the small size of the study population, and patients were not followed up for long to see further clinical, laboratory, and histopathological changes of renal status.

\section{REFERENCES}

1. D’Cruz DP. Systemic lupus erythematosus. BMJ 2006;332:890-4.

2. Manzi SM, Stark VE, Ramsey-Goldman R. Systemic lupus erythematosus: Epidemiology and classification of systemic lupus erythematosus. In: Hochberg MC, Silman AJ, Smolen JS, Weinblatt M,
Weisman M., editors. Rheumatology. 3rd ed. St. Louis: CV Mosby; 2003. p. 1291-6.

3. Uramoto KM, Michet CJ Jr, Thumboo J, Sunku J, O’Fallon WM, Gabriel SE. Trends in the incidence and mortality of systemic lupus erythematosus, 1950-1992. Arthritis Rheum 1999;42(1):46-50.

4. Kumar A, Malaviya AN, Singh RR, Singh YN, Adya CM, Kakkar R. Survival in patients with systemic lupus erythematosus in India. Rheumatol Int 1992;12(3):107-9.

5. Nezhad ST, Sepaskhah R. Correlation of clinical and pathological findings in patients with lupus nephritis: A five-year experience in Iran. Saudi J Kidney Dis Transpl 2008;19(1):32-40.

6. Christopher-Stine L, Siedner M, Lin J, Haas M, Parekh H, Petri M, et al. Renal biopsy in lupus patients with low levels of proteinuria. J Rheumatol 2007;34(2):332-5.

7. Weening JJ, D'Agati VD, Schwartz MM, Seshan SV, Alpers CE, Appel GB, et al. The classification of glomerulonephritis in systemic lupus erythematosus revisited. J Am Soc Nephrol 2004;15:241-50.

8. Sanker R, Biswas R, Bhattacharjee B. Clinical and histological profile of lupus nephritis patients attending in a tertiary care center. J Integr Nephrol Androl 2015;2(3):81-4.

9. Cameron SJ. Lupus nephritis. Disease of the month. J Am Soc Nephrol 1999; 10:413-22.

10. Esdaile JM, Levinton C, Federgreen W, Hayslett JP, Kashgarian M. The clinical and renal biopsy predictors of long-term outcome in lupus nephritis: A study of 87 patients and review of the literature. Q J Med 1989;72(269):779-833.

11. Tan EM, Cohen AS, Fries JF, Masi AT, McShane DJ, Rothfield NF, et al. The 1982 revised criteria for the classification of systemic lupus erythematosus. Arthritis Rheum 1982;25(11):1271-7.

12. Shobha V, Prakash R, Arvind P, Tarey SD. Histopathology of lupus nephritis: A single-center, cross-sectional study from Karnataka, India. IJRCI 2014;2(1):OA3.

13. Austin HA $3^{\text {rd }}$, Boumpas DT, Vaughan EM, Balow JE. Predicting renal outcomes in severe lupus nephritis: Contributions of clinical and histologic data. Kidney Int 1994;45(2):544-50.

14. Nasri H, Ahmadi A, Baradaran A, Momeni A, Nasri P, Mardani S, et al. Clinicopathological correlations in lupus nephritis; A single center experience. J Nephropathol 2014;3(3):115-20.

15. Gomaa W, Bahlas S, Habhab W, Mushtaq M, Al-Ghamdi S, AlMaghrabi J. Clinicopathological characteristics of lupus nephritis in western region of Saudi Arabia: An experience from two tertiary medical centres. J Microscopy Ultrastruct 2014;2:12-9.

16. Neumann K, Wallace DJ, Azen C, Nessim S, Fichman M, Metzger AL, et al. Lupus in the 1980s: III. Influence of clinical variables, biopsy, and treatment on the outcome in 150 patients with lupus nephritis seen at a single Center. Semin Arthritis Rheum 1995;25(1):47-55.

17. Pollak VE, Pirani CL, Schwartz FD. The natural history of the renal manifestations of systemic lupus erythematosus. J Lab Clin Med 1964;63:537-50.

18. Appel GB, Silva FG, Pirani CL, Meltzer JI, Estes D. Renal involvement in systemic lupud erythematosus (SLE): A study of 56 patients emphasizing histologic classification. Medicine (Baltimore) 1978;57(5):371-410.

19. Austin HA $3^{\text {rd }}$, Muenz LR, Joyce KM, Antonovych TA, Kullick ME, Klippel JH, et al. Prognostic factors in lupus nephritis. Contribution of renal histologic data. Am J Med 1983;75(3):382-91.

20. Mok CC, Wong RW, Lau CS. Lupus nephritis in Southern Chinese patients: Clinicopathologic findings and long-term outcome. Am J Kidney Dis 1999;34:315-23.

21. Wallace DJ. The clinical presentation of SLE. In: Wallace DJ, Hahn BH, editors. Dubois's Systemic Lupus Erythematosus. $4^{\text {th }}$ ed. Philadelphia, PA: Lea \& Febiger; 1992. p. 317-21.

22. Yoo CW, Kim MK, Lee HS. Predictors of renal outcome in diffuse proliferative lupus nephropathy: Data from repeat renal biopsy. Nephrol Dial Transplant 2000;15:1604-8. 